\title{
Chapter 9 \\ The Potential for Producing Rice for Feed and Whole-Crop Rice Silage in Radiation-Contaminated Areas
}

\author{
Seiji Nobuoka
}

\begin{abstract}
Neither whole rice plants for silage nor unhulled rice grains can be used as livestock feed if their radiation concentration exceeds the threshold limit of $100 \mathrm{~Bq} / \mathrm{kg}$. However, the results outlined here confirm that even in paddies with a comparatively high radioactive cesium soil concentration of $2,600 \mathrm{~Bq} / \mathrm{kg}$, this threshold can be met by plowing and applying zeolite as a decontamination measure. This finding is positive news for areas that have suffered radioactive contamination. The study also found the level of radiation in unhulled grains of fodder rice to be below the $100 \mathrm{~Bq} / \mathrm{kg}$ limit, meaning that the rice was usable as livestock feed.
\end{abstract}

Keywords Cesium $\bullet$ Rice $\bullet$ Feed $\bullet$ Silage $\bullet$ Livestock $\bullet$ Zeolite $\bullet$ Potash

\subsection{Introduction: Research Objectives}

On August 9, 2013, the Japanese Ministry of Agriculture, Forestry and Fisheries released a map showing concentrations of radionuclide in farmland soil. According to this map, soil radiation concentration exceeds $5,000 \mathrm{~Bq} / \mathrm{kg}$ of radioactive cesium-134 and -137 combined in an estimated 7,500 ha of agricultural land in Fukushima Prefecture, requiring decontamination by physical means. Additionally, an estimated 53,822 ha of agricultural land in Fukushima Prefecture is contaminated with a concentration of $1,000-5,000 \mathrm{~Bq} / \mathrm{kg}$. Rice paddies account for three quarters of this area. Since 2011, in line with the policy on rice planting set by the Japanese government's Nuclear Emergency Response Headquarters, cultivation of rice for consumption has been prohibited in paddies where radioactive contamination exceeds $5,000 \mathrm{~Bq} / \mathrm{kg}$. This policy is based on an estimated radiation transfer

\footnotetext{
S. Nobuoka $(\square)$

Laboratory of Livestock Farming Management, Department of Animal Science, Faculty of Agriculture, Tokyo University of Agriculture,

Funako 1737, Atugi, Kanagawa 243-0034, Japan

e-mail: s3nobuok@nodai.ac.jp 
factor from soil to unpolished rice of 0.1 , and the planting prohibition remained in place as of 2013.

In 2012 the same prohibition was also placed on some paddies with a soil cesium concentration below $5,000 \mathrm{~Bq} / \mathrm{kg}$ because the level of radioactive cesium permissible in unpolished rice for human consumption had been lowered from 500 to $100 \mathrm{~Bq} / \mathrm{kg}$. In 2013 paddy land has been divided into three broad categories based on the level of soil contamination: (1) planting prohibited (other than for experimental/nonconsumption purposes), (2) test planting permitted (in preparation for resumption of cultivation), and (3) cultivation and shipment permitted (under fully controlled conditions). With the establishment of these categories, a path toward agricultural recovery has begun to emerge.

The Laboratory of Livestock Farming Management is part of the Department of Animal Science at Tokyo University of Agriculture. Since 2011 the laboratory has been participating in the university's East Japan Assistance Project, working to develop decontamination measures with other laboratories such as the Department of Applied Biology and Chemistry's Laboratory of Agricultural Production and Environmental Chemistry.

The associated research focuses on rice grown for livestock feed in paddies with a radiation concentration of $5,000 \mathrm{~Bq} / \mathrm{kg}$ or less. Its aim is to develop a method that uses potassium fertilizer and zeolite material to prevent rice for feed from absorbing radioactive cesium, and to confirm its safety for use as feed by giving the harvested product (rice for feed or whole-crop rice silage) to livestock for consumption.

\subsection{Tests to Prevent Cesium Absorption in Livestock Feed Rice}

We believe that, in addition to physical decontamination measures, the development of methods to prevent transfer of radioactive cesium from soil to crops is an effective means of assisting the areas affected by the nuclear accident. However, the majority of research into rice paddy decontamination methods has focused on rice for human consumption, and very little testing and research has been conducted thus far in relationship to crops such as rice for livestock feed.

Recent years have witnessed rapid growth in the Japanese land area used for cultivation of domestically grown livestock feed in the form of rice grains for fodder and whole rice plants for silage. Nationwide, 33,726 ha of fodder rice and 31,157 ha of rice plants for silage were produced in 2014, amounting to a total of 64,883 ha. In Fukushima Prefecture, meanwhile, 893 ha of fodder rice and 762 ha of rice plants for silage were produced in 2014. Of course, rice for livestock feed and other crops can be grown in paddies with a soil radiation level of $5,000 \mathrm{~Bq} / \mathrm{kg}$ or lower in the same way as rice for human consumption. It is therefore essential to develop methods to prevent cesium from being absorbed into the stalks, leaves, and grains used for livestock feed to ensure the safety of the products derived from animals to which it is fed. To this end, we began conducting tests to prevent cesium absorption in rice paddies in the Haramachi district of Minamisoma City in Fukushima Prefecture. The following is an overview of the test site. 


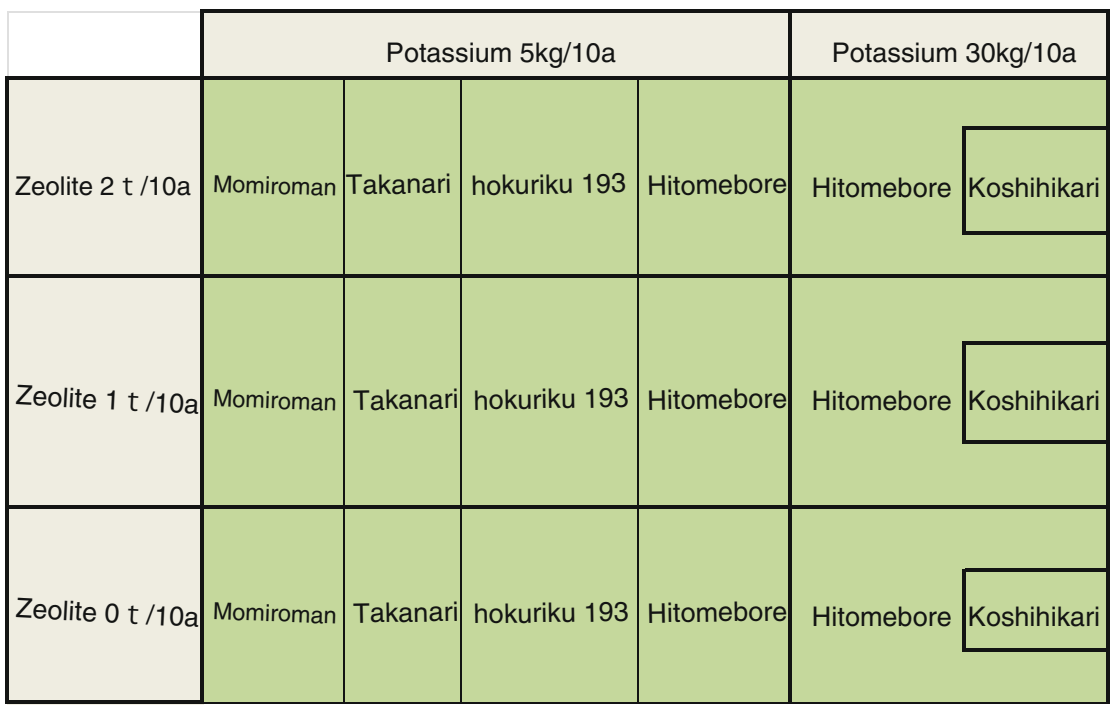

Fig. 9.1 Allocation of test plots and rice varieties

\section{Test site}

Rice paddies covering 30 ares in the Haramachi district of Minamisoma City, Fukushima Prefecture $(20.8 \mathrm{~km}$ from the Fukushima Daiichi nuclear power station)

2. Allocation of test plots

Zeolite was differentiated by volume into control plots (with no zeolite applied) and test plots (with either $1 \mathrm{t} / 10$ ares or $2 \mathrm{t} / 10$ ares of zeolite applied). Potash fertilizer (potassium chloride) was applied in the zeolite plots, differentiating by volume into standard-potassium plots ( $5 \mathrm{~kg} / 10$ ares) and high-potassium plots $(30 \mathrm{~kg} / 10$ ares $)$.

3. Rice varieties tested

We tested Momiroman, Takanari, and Hokuriku 193 as livestock feed varieties, and Hitomebore and Koshihikari as varieties for human consumption (Fig. 9.1).

4. We conducted growth studies and sampled rice plants and soil at each stage of growth.

5. We measured the concentration of radioactive cesium in sampled rice plants and soil using a germanium semiconductor detector.

\subsection{Results of Tests to Prevent Cesium Absorption in Rice for Livestock Feed}

The following are results of analysis of radioactive cesium concentrations (combined totals of cesium-134 and -137) in paddy soil at the test site in the Haramachi district of Minamisoma City, Fukushima Prefecture. 


\subsubsection{Radioactive Cesium Concentrations Measured in Test Paddies}

The initial concentration of radioactive cesium at the test site (before plowing) was $2,600 \mathrm{~Bq} / \mathrm{kg}$. After the paddies were plowed to reduce radioactive cesium concentration and decontaminate the soil, then replowed with potash fertilizer with or without zeolite, radioactive cesium concentration in the paddy soil fell by half, to approximately $1,400 \mathrm{~Bq} / \mathrm{kg}$.

\subsubsection{Radioactive Cesium Concentrations at Various Soil Depths}

The concentration of radioactive cesium at various soil depths was measured while the rice plants were growing. In soil samples taken on July 19, 2012, concentrations ranged from 1,008 to $1,586 \mathrm{~Bq} / \mathrm{kg}$ at $0-5 \mathrm{~cm}$, from 798 to $1,641 \mathrm{~Bq} / \mathrm{kg}$ at $5-10 \mathrm{~cm}$, and from 212 to $1,113 \mathrm{~Bq} / \mathrm{kg}$ at $10-15 \mathrm{~cm}$. The concentration in the soil deeper than 15-20 cm was far lower, less than $200 \mathrm{~Bq} / \mathrm{kg}$ (Fig. 9.2).

In the next soil samples taken on September 12, 2012, concentrations ranged from 1,183 to $1,696 \mathrm{~Bq} / \mathrm{kg}$ at $0-5 \mathrm{~cm}, 1,102$ to $1,782 \mathrm{~Bq} / \mathrm{kg}$ at $5-10 \mathrm{~cm}$, and 449 to $1,398 \mathrm{~Bq} / \mathrm{kg}$ at $10-15 \mathrm{~cm}$. Although levels in the deeper soil were lower, measuring

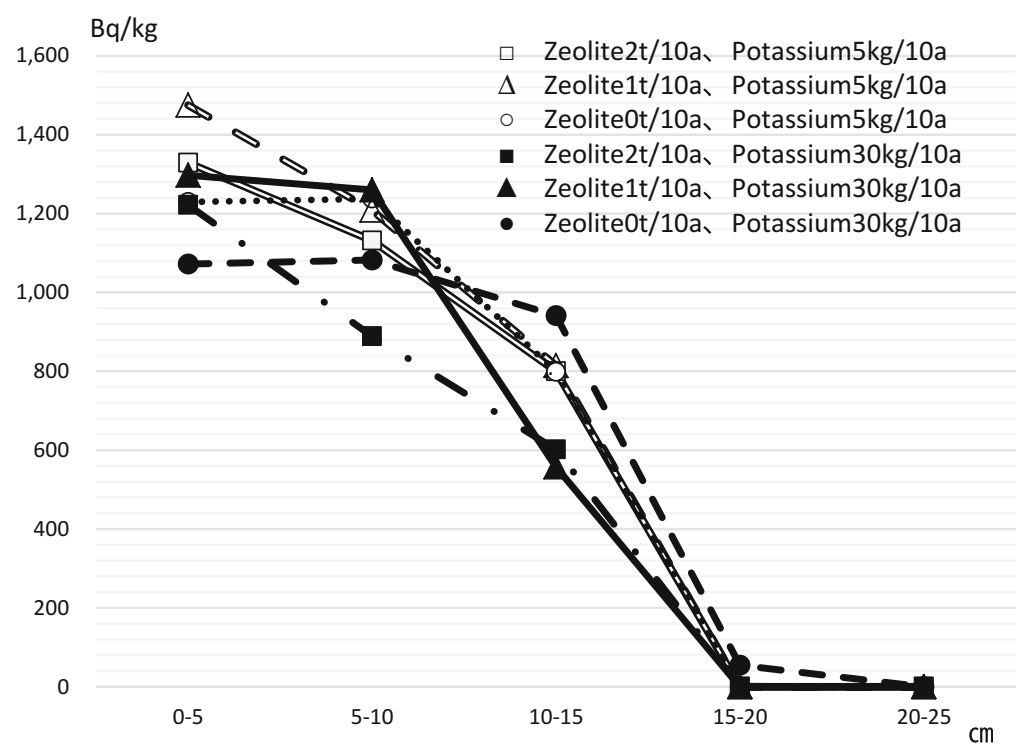

Fig. 9.2 Concentration of radioactive cesium at various soil depths (Samples taken July 19, 2012) 


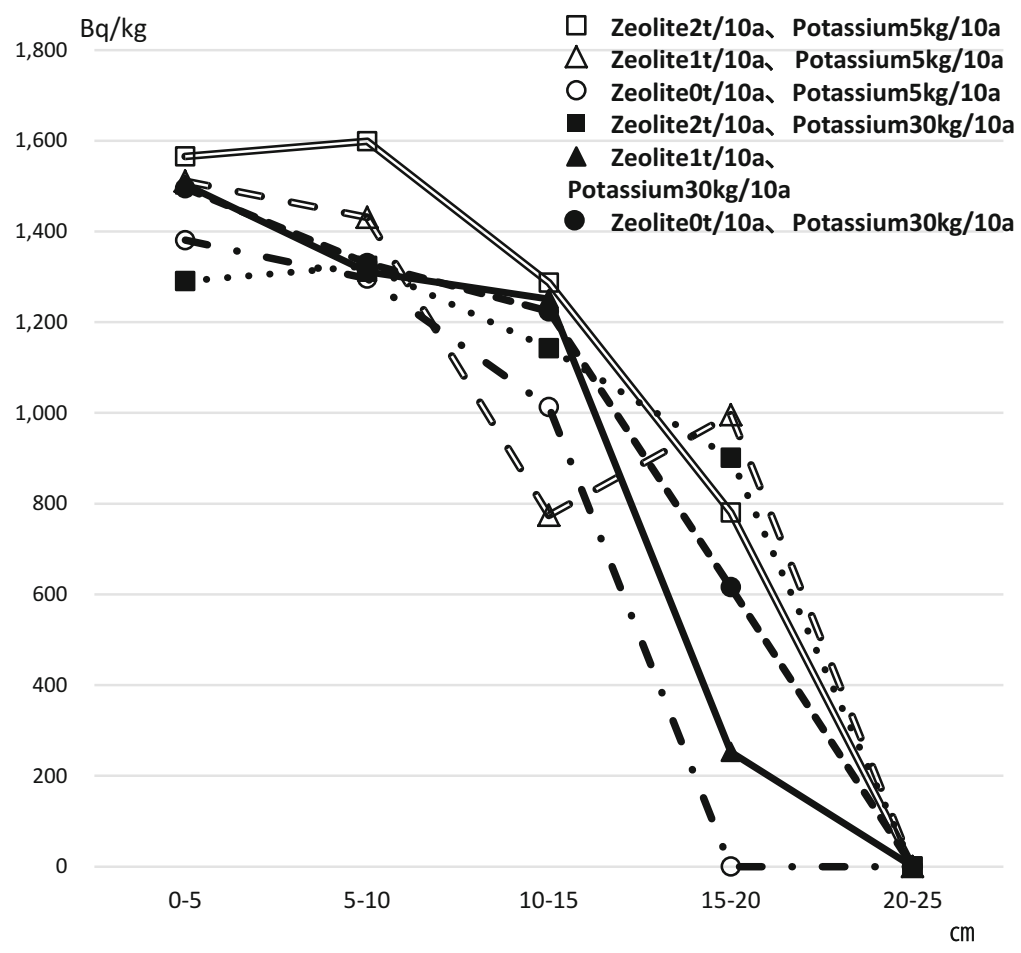

Fig. 9.3 Concentration of radioactive cesium at various soil depths (Samples taken September 12, 2012)

27 to $843 \mathrm{~Bq} / \mathrm{kg}$ at $15-20 \mathrm{~cm}$, and 12 to $155 \mathrm{~Bq} / \mathrm{kg}$ at $20-25 \mathrm{~cm}$, radiation concentration in the subsoil had gradually increased compared to the July samples (Fig. 9.3).

The foregoing results therefore show that radioactivity is moving to the subsoil, albeit gradually. Although the actual level of the radiation was not particularly high, the situation needs to be monitored in future as the roots of rice plants extend to the subsoil.

\subsubsection{Radioactive Cesium Concentration in Whole Rice Plants for Silage}

The tests conducted in Minamisoma City, Fukushima Prefecture, to study prevention of radioactive cesium absorption in rice for livestock feed, mainly focused on the application of zeolite. Our findings showed that only two varieties of rice plants for silage had a radioactive cesium concentration exceeding $100 \mathrm{~Bq} / \mathrm{kg}$ at the time of harvest (September 12, 2012): Momiroman [in a no-zeolite, standard-potassium (5 kg/10 ares) plot], and Hokuriku 193 (also in a no-zeolite, standard-potassium plot). None of the samples from the plots applied with a combination of both zeolite 


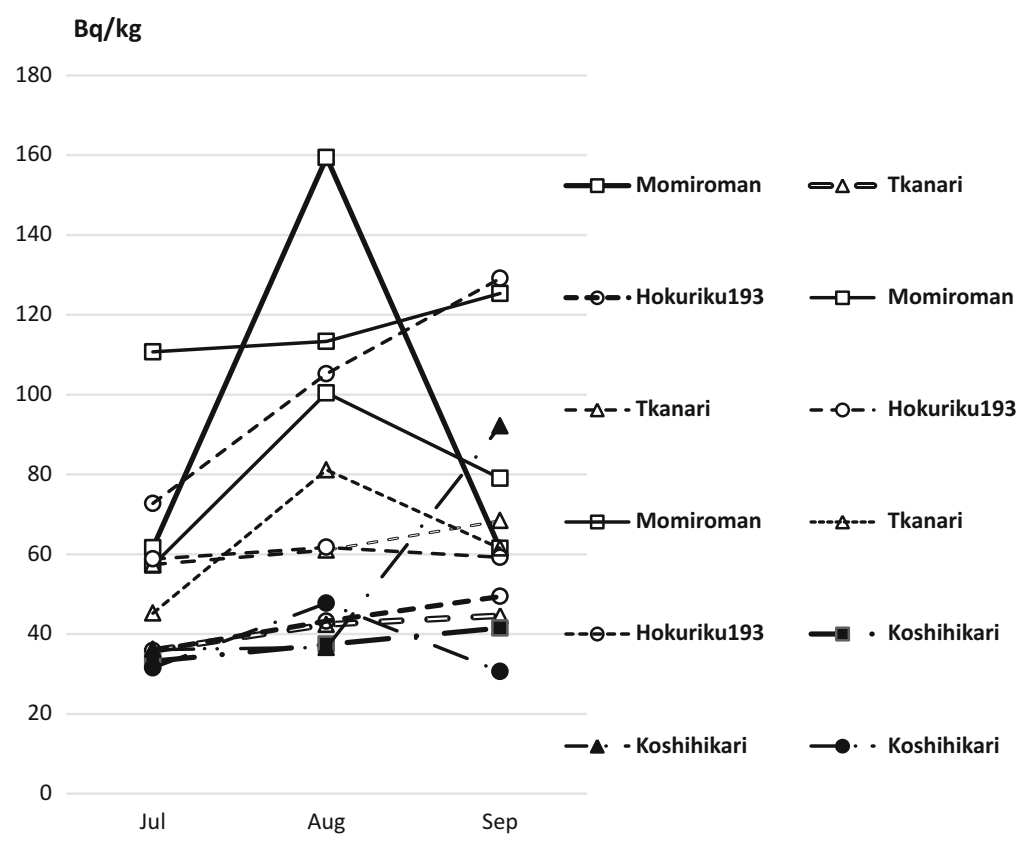

Fig 9.4 Radioactive cesium concentration in rice plants for silage by variety, stage of growth, and amount of zeolite/potash fertilizer applied

and potash fertilizer exceeded the $100 \mathrm{~Bq} / \mathrm{kg}$ government safety limit for use as livestock feed (Fig. 9.4).

The average cesium concentration in rice plants for silage at the time of harvest in September was $51.8 \mathrm{~Bq} / \mathrm{kg}$ in the 2-t zeolite plot, $68.9 \mathrm{~Bq} / \mathrm{kg}$ in the 1-t zeolite plot, and $105.3 \mathrm{~Bq} / \mathrm{kg}$ in the 0-t zeolite plot. Compared with the 0-t zeolite plot, absorption was reduced to $49 \%$ in the 2-t zeolite plot and $65 \%$ in the 1-t zeolite plot.

Variation among rice varieties was observed, with cesium concentrations in the 2-t zeolite plot of $61.4 \mathrm{~Bq} / \mathrm{kg}$ in Momiroman, $49.6 \mathrm{~Bq} / \mathrm{kg}$ in Hokuriku 193, and 44.6 Bq/kg in Takanari. Although definite conclusions cannot be drawn because of the small sample size, it is believed that Momiroman absorbs cesium more readily than other varieties such as Takanari and Hokuriku 193.

The radioactive cesium concentration was $41.5 \mathrm{~Bq} / \mathrm{kg}$ in the unhulled grains of Koshihikari rice for human consumption grown as a control (in a plot containing $2 \mathrm{t} / 10$ ares of zeolite and $30 \mathrm{~kg} / 10$ ares of potash). This finding suggests that the rice varieties used for livestock feed have a slightly higher tendency to absorb cesium than the varieties grown for human consumption.

Considering cesium concentration in the rice plants at various stages of growth, the July 19 level in the 2-t zeolite plot of Momiroman was $61.6 \mathrm{~Bq} / \mathrm{kg}$, whereas the concentration in the 0 -t plot was approximately double this at $110.8 \mathrm{~Bq} / \mathrm{kg}$. This test result confirmed the effectiveness of zeolite in reducing cesium absorption. Additionally, the August and September analysis results showed a trend toward higher levels of radioactive cesium in plants compared to the July 19 analysis data. 
However, the analysis data from September 12 returned scattered results, with cesium concentration declining in some plants compared to August and September while conversely increasing in others.

Whole rice plants for silage are harvested and bale-rolled in their entirety, including stalks and leaves, during the milk-ripe stage before the grains have hardened. It is therefore important that radioactive cesium concentration in August and September does not exceed the $100 \mathrm{~Bq} / \mathrm{kg}$ safety threshold for livestock feed. However, there was an issue in this regard, as the concentration in the livestock feed rice varieties Momiroman and Hokuriku 193 exceeded $100 \mathrm{~Bq} / \mathrm{kg}$ when zeolite was not administered. When cultivating rice for use as livestock feed, it is therefore necessary to administer large quantities of zeolite and potash fertilizer as a means of reducing radioactive cesium absorption.

\subsubsection{Radioactive Cesium Concentration in Unhulled Rice Grains for Fodder}

Concentrations of radioactive cesium in unhulled rice grains for use as fodder are outlined next. Radioactive cesium concentration in unhulled Takanari rice was $45.4 \mathrm{~Bq} / \mathrm{kg}$ in the 2-t zeolite plot, $65.4 \mathrm{~Bq} / \mathrm{kg}$ in the 1-t zeolite plot, and $47.5 \mathrm{~Bq} / \mathrm{kg}$ in the 0 -t zeolite plot (Fig. 9.5).

Cesium concentration in unhulled grains of Takanari fodder rice was below $100 \mathrm{~Bq} / \mathrm{kg}$ in both test plots as well as the control plot. However, these results did not provide enough evidence to draw a clear conclusion that zeolite was effective in reducing absorption of radioactive cesium. We are currently continuing on-site tests using a combination of zeolite and potash fertilizer for the 2013 crop.

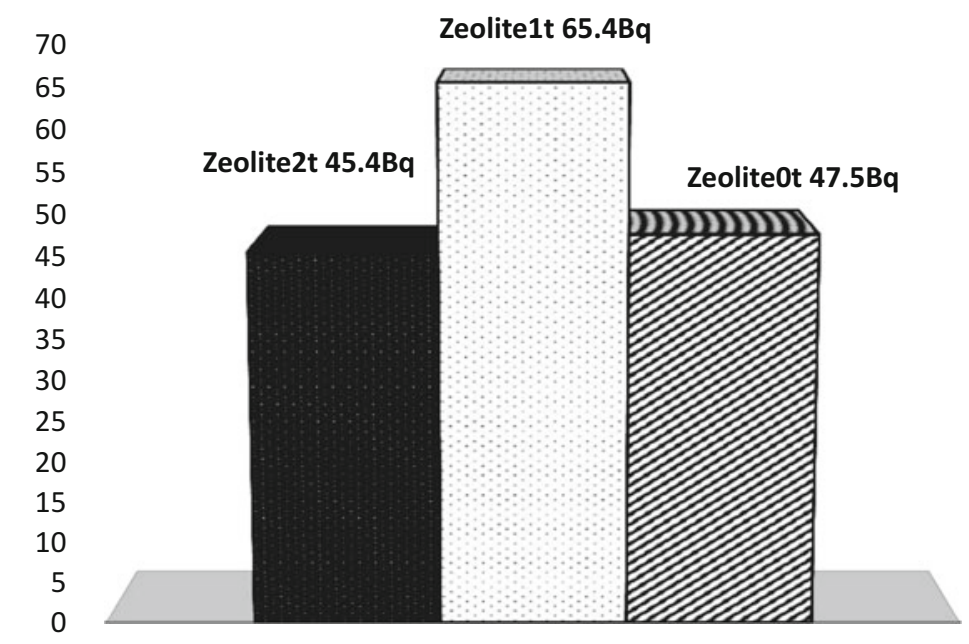

Fig. 9.5 Concentration of radioactive cesium in unhulled Takanari rice grains by amount of zeolite applied 


\subsection{Summary}

Neither whole rice plants for silage nor unhulled rice grains can be used as livestock feed if their radiation concentration exceeds the threshold limit of $100 \mathrm{~Bq} / \mathrm{kg}$. However, the results outlined here confirm that even in paddies with a comparatively high radioactive cesium soil concentration of $2,600 \mathrm{~Bq} / \mathrm{kg}$, this threshold can be met by plowing and applying zeolite as a decontamination measure. This finding is positive news for areas that have suffered radioactive contamination. The study also found the level of radiation in unhulled grains of fodder rice to be below the $100 \mathrm{~Bq} / \mathrm{kg}$ limit, meaning that the rice was usable as livestock feed.

Besides testing the efficacy of zeolite efficacy, we also considered the economic feasibility of zeolite application as a means of reducing cesium absorption. In addition to the labor required to apply zeolite, the material itself costs around 75 yen per kilogram. Application of 2 tons per 10 ares would therefore incur a cost of 150,000 yen per 10 ares for the material alone. Alternatively, application of 1 ton per 10 ares would cost 75,000 yen, and this amount would be eligible for compensation as decontamination costs. Zeolite is, moreover, straightforward to use: it is easily applied with a broadcast spreader and a single application fixes cesium, making application every year unnecessary. From an economic and practical point of view, the findings of this study can therefore be put into effect immediately.

With the 2013 crop, the planting prohibitions have been relaxed. Cultivation is possible even in contaminated areas, on condition that the land is decontaminated

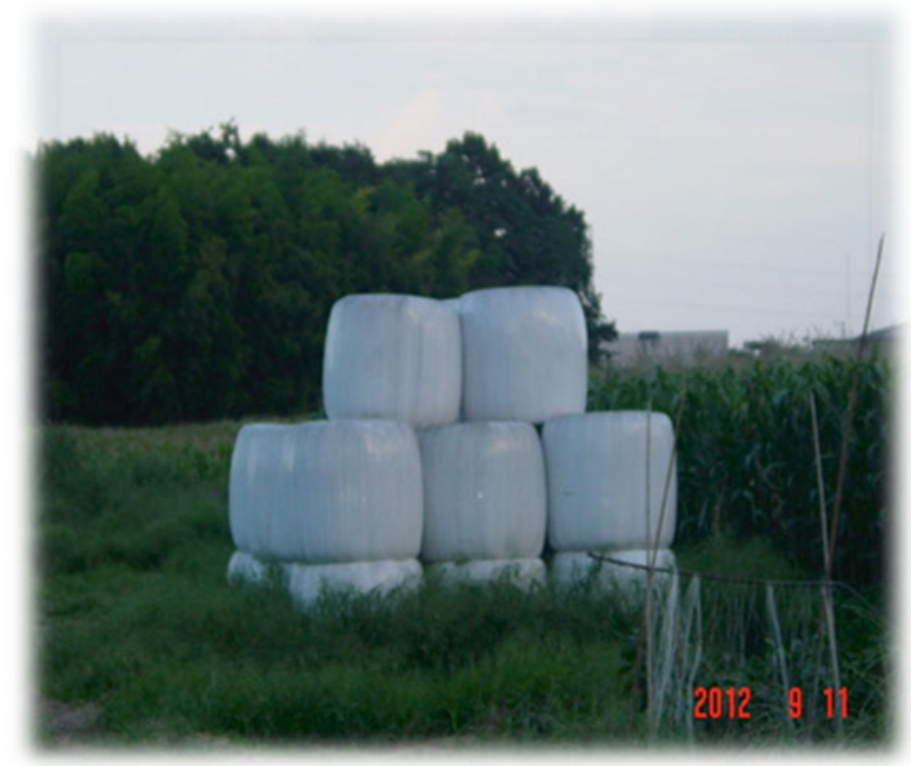

Fig. 9.6 Italian ryegrass silage $(34.8 \mathrm{~Bq} / \mathrm{kg})$ 


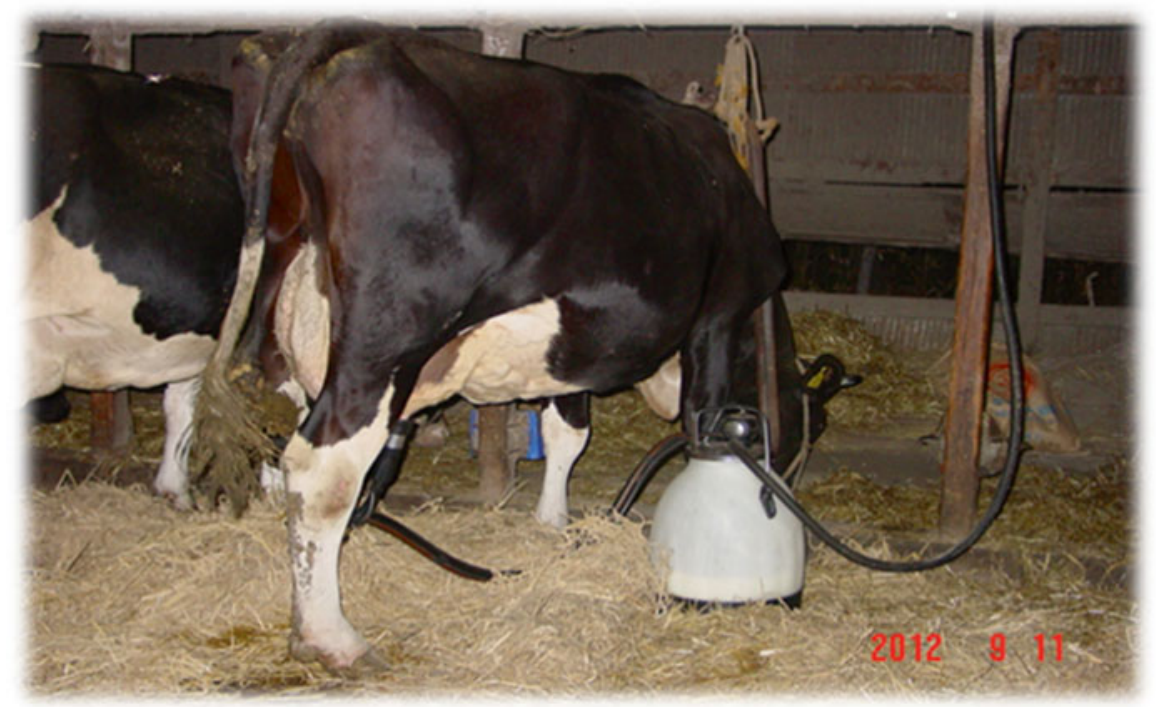

Fig. 9.7 Feeding test for dairy cows

by such means as deep plowing or reversing the soil and spreading potash material, whereas each bag of rice must be radiation tested before shipment. Zones have been designated where test planting is permitted in preparation for resumption of cultivation, and planting has recommenced in selected areas. The site used for this study in the Haramachi district of Minamisoma City was designated as a test planting zone in 2013, so there will be a rice harvest this year.

We are conducting our Haramachi study jointly with two local farmers, one of whom planted 8 ha of rice in 2013, leading the way toward the revival of agriculture in the district. After seeing the example set by this farmer and the tests conducted by Tokyo University of Agriculture, another farmer in the area has expressed a desire to begin growing rice for livestock feed in 2014. Thus, our tests are gradually helping to provide a foothold for getting the district's agricultural revival under way.

At the same time, actual numeric data are needed to verify the extent to which radiation transfers to livestock products even if animals are fed rice plants with a cesium concentration lower than the limit of $100 \mathrm{~Bq} / \mathrm{kg}$. In a 2012 study targeting dairy farmers in the Nasu area of Tochigi Prefecture, dairy cows were fed Italian ryegrass silage with a radioactive cesium concentration of $34.8 \mathrm{~Bq} / \mathrm{kg}$ over a 6-month period. Subsequently, the cesium concentration in the raw milk was measured twice using a germanium semiconductor detector, and on neither occasion was any trace of cesium found (the limit of detection for cesium-137 is $1.5-2.3 \mathrm{~Bq} /$ kg) (Figs. 9.6 and 9.7). 
From these findings we can infer that cultivation of rice grains for use as fodder and whole rice plants for silage is likely to be feasible in radiation-contaminated areas.

Open Access This chapter is distributed under the terms of the Creative Commons Attribution Noncommercial License, which permits any noncommercial use, distribution, and reproduction in any medium, provided the original author(s) and source are credited. 